\title{
MESSAGE
}

\section{From the Executive}

While I was attending the Melbourne International AIDS Society (IAS) conference in July, I must admit that I was surprised at the announcement by the Minister of Health on the change in our eligibility criteria for antiretrovirals (ARVs). He announced that, to be in line with the World Health Organization, all HIV-infected individuals with a $\mathrm{CD} 4^{+}$count $<500$ cells $/ \mu$ should be started on antiretroviral therapy (ART), and that all HIV-infected pregnant women should initiate lifelong therapy, namely Option B+. The Society congratulates the National Department of Health on their willingness to amend South African ARV policy in order to treat as many individuals as possible.

In terms of raising the $\mathrm{CD} 4^{+}$entry level to $500 \mathrm{cells} / \mu \mathrm{l}$, it must be noted that while randomised, clinical trial data on the clinical benefit of ART in patients with $\mathrm{CD} 4^{+}$counts $>350 \mathrm{cells} / \mu \mathrm{l}$ are not yet available, we do recognise that there are advantages to having more people on medication. There is a clear transmission-prevention benefit in discordant couples and there are accumulating data in the community setting.

So, as clinicians, we need to up our counselling game. The task of taking lifelong medication is an onerous one. Our current first line is not forgiving of missed doses. We, as healthcare workers, should have a thorough discussion with patients about the potential benefits, uncertainties and side-effects of medication If patients are motivated to stick to their treatment, they should be prescribed ART; if they do not yet feel ready, they should be given time to work through the issues needed to adhere to therapy. Obviously, this would be done with close monitoring of their $\mathrm{CD} 4^{+}$counts.

On another note, September 2014 brings our next conference. It promises to be packed with interesting debates, excellent plenaries and top-notch speakers. For those of you who are attending, enjoy the opportunity to network and connect

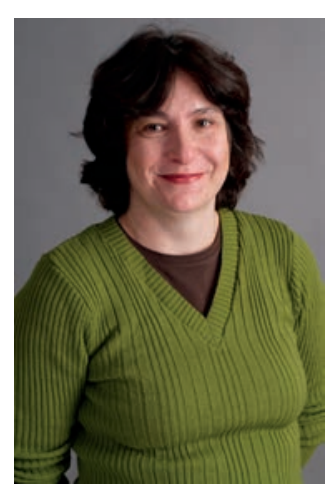
with other HIV clinicians. For those of you who cannot make it, follow our Facebook page (http:// www.facebook.com/SAHIVSoc), Twitter account (@SAHIVSoc) and the media.

\section{Francesca Conradie}

President: Southern African HIV Clinicians Society fconradie@witshealth.co.za 